\title{
The Application of Web Data Mining Technology in E-commerce
}

\author{
Zhao Lixia ${ }^{1, a, *}$, Jin Wei ${ }^{2}$ \\ ${ }^{1}$ Department of Information Engineering, Liaoning Institute of Technology, 121000, China \\ ${ }^{2}$ Experimental Center of Bohai University, 121000, China \\ a email: 13840686460@139.com \\ *corresponding author
}

Keywords: Web, Data Mining Technology, E-commerce, Application Path

\begin{abstract}
With the rapid development of social science and technology in our country, more and more new technologies appear in people's lives, and gradually change people's way of life, such as: cloud computing technology, big data technology, Web data mining technology and so on. The big data era has been brought, data has become an important element in people's daily life, and the amount of data people process is increasing, how to deal with a large amount of data quickly and accurately, in a large number of data centers to find useful information, is the current people focus on thinking. From the point of view of e-commerce, this paper briefly analyzes Web data mining technology and its application points in e-commerce, and probes into the application path of Web data mining technology in e-commerce in depth.
\end{abstract}

\section{Overview of Web Data Mining Technology}

Web data mining technology can be divided into: Web content mining technology, Web use mining technology and Web structure mining technology. In the electronic commerce of modern society, the staff often need to face the massive data information, how to find the demand information accurately from these information, explore the development law in the data, grasp the intention customer and the development direction is the basic work link of the electronic commerce staff. Based on this, the staff should combine the web data mining technology, start from the data preparation, the selection algorithm, the system architecture, the result analysis and so on, construct the data mining system which can meet the needs of e-commerce in an all-round way, so as to improve the efficiency of e-commerce work, strengthen the online transaction performance, and promote the development of enterprises.

Web data mining technology (figure 1) is a new form of data processing technology, in the process of deepening the development of e-commerce, will produce a lot of data, including: target customer information, transaction information, commodity information and so on. It is necessary for the staff to use different computer technology and software to screen and capture the mixed information, and then apply it to the specific mathematical model to concentrate on the processing of the data, so as to analyze the potential information in the data, improve the accuracy of the information push of electronic commerce, and promote the online education of electronic commerce, so as to realize the purpose of promoting the development of enterprises and the operation cost of their enterprises [1].

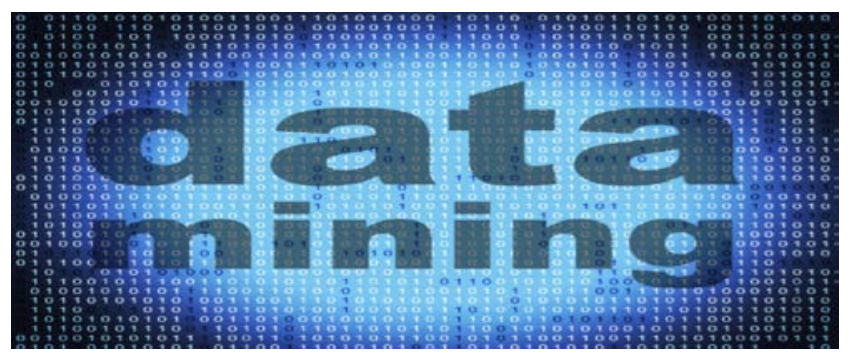

Figure 1 Web data mining technology trademark 
In the process of using Web data mining technology, e-commerce workers can divide it into three categories, according to different data information, adopt different data mining technology, so as to improve work efficiency. For example, if the data information is text information and multimedia information, then the staff can use the content mining technology to explore the content information on the Web page, so as to achieve the work goal. In this process, the staff use different data mining technology, we should pay attention to adjust the grammar and algorithm, fully meet the needs of technology application while reducing the cost of data analysis, improve work efficiency, and strengthen the analysis effect of data mining.

\section{Application of Web Data Mining Technology in Electronic Commerce}

The first step is to prepare the data. Staff should combine data mining objectives and work objectives to prepare the corresponding data, so as to improve the success rate of modeling and data analysis accuracy. The staff should make clear the data files, such as: registration information, browsing information, log, login record, transaction information and commodity information; also combine the data capture technology, make clear the data capture limit, make full use of the broadband and target server, so as to ensure the data capture system can run long-term and stablely; also save the grabbed information into the data module to form a complete data resource, and optimize and perfect the module, so as to ensure the module's adaptability to the massive information.[2].

The second step is to select the appropriate algorithm (Fig .2). Algorithm is the main means to analyze data, whether to choose a reasonable algorithm, directly affect the efficiency of the system, affect the results of data analysis. Therefore, in the process of selecting the algorithm, the staff should carry out the basic analysis according to the commodity information on the e-commerce online platform and the docking customer group, and grasp the transaction characteristics among them, so as to choose the algorithm that can meet the needs of data analysis to the maximum extent. In the process of actual selection, the staff can directly choose Apriori as the basic running algorithm, and then combine with the actual situation, improve the algorithm, so as to serve as the basic framework of the system to build the foundation.

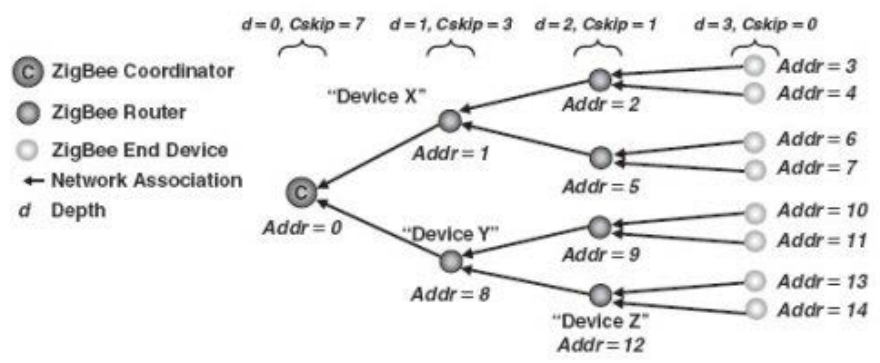

Figure 2 Selection and application of algorithms (distributed computing algorithms)

The third step is to build a system architecture. In the process of using e-commerce in Web data mining technology, if the staff want to construct the system architecture, it is necessary to make clear the meaning and function of the system architecture and grasp its realization way. In the process of concrete operation, the staff should give priority to the key points of the system operation, and enrich the actual development form of electronic commerce on the basis of ensuring the expansion of the application scope of information network technology. Based on this, the staff should optimize the design according to the different forms of e-commerce, and make the resulting data analysis more how to target the consumer demand of the customer, and also design the simple and bright page to improve the convenience of e-commerce and facilitate the transaction [3].

The fourth step is to analyze the data mining results. Results Analysis is an important link in the application of web data mining technology in e-commerce. In the process of system operation, the staff should adopt the way of manual intervention, deeply analyze the operation combination of the system, and find out the problems and potential security hidden danger in time, so as to ensure the safety in the transaction process. In addition, the optimization of the system can improve the overall 
level of e-commerce and fully meet the needs of industry development and enterprise operation.

\section{The Application Path of Web Data Mining Technology in Electronic Commerce}

(1) Grasp customer groups and improve the personalized level of e-commerce services

Using web data mining technology in e-commerce, the staff should combine the enterprise's commodity situation, according to the previous customer transaction record and work experience, grasp the customer group characteristics, analyze the customer's psychological needs and transaction needs, put forward the "individualized" service concept, and improve the customer's transaction satisfaction. In the process of actual data mining, the staff should classify the value of the target customer and the existing customer, so as to put forward the customer with insufficient value and focus on the customer with greater value. In addition, we can make use of data mining technology to carry out personalized design and enrich the process of e-commerce transaction by combining its own management characteristics [4].

(2) Improve the overall level of the site, optimize the customer online access experience

Using web data mining technology in e-commerce, staff should use web data mining technology to carry out website construction and optimization, improve the overall level of the website, create a good online trading environment for customers, strengthen the online access experience of customers, and improve the transaction completion rate. Staff members can identify the most frequent ways to manage and place key commodity information in conjunction with the site visit rate; they can also strengthen the design of commodity information, emphasize the display links of commodities, and encourage customers to visit actively; they can also analyze customer visit browsing records, explore the direction of customer visit expectations, rationalize the design of commodity navigation links, guide customers to browse in depth and improve the efficiency of ecommerce transactions.

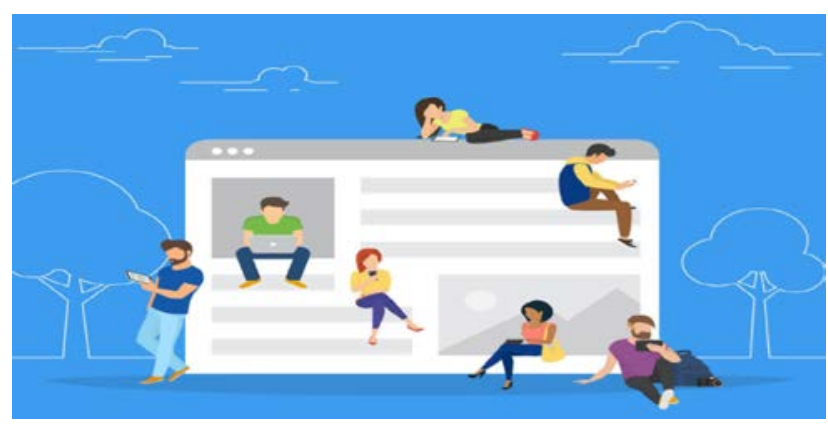

Figure 3 Customer's concept map on the website

(3) Designing website features to facilitate electronic transactions

Using Web data mining technology in e-commerce, the staff can also design the enterprise website with its characteristics, and make the overall style of the website conform to the characteristics of the operation and commodity of the e-commerce enterprise, or introduce more functional modules to meet the diversified needs of the customer in all directions, and promote the online transaction strongly. The staff can use the data mining technology to analyze the website to browse the customer's hobby, age, consumption preference, demand, work and so on information, set up the dynamic display page, will be able to arouse the customer's interest commodity information to carry on the directional broadcast, thus satisfies the different age group, the post, the region customer's demand, expands the enterprise service scope, enhances the operation efficiency [5].

(4) introducing advanced engines and regularly launching high-quality advertisements

Using Web data mining technology in electronic commerce, staff can use Web data mining technology to carry out data analysis, combined with the results of analysis, according to the needs of customers, different engine systems are introduced to optimize engine functions. Staff should optimize the setting of keywords, improve the degree of connection between keywords and customers, improve the level of retrieval services; to adjust the layout of web pages, to provide 
more convenient browsing and retrieval services, to analyze customer history browsing records, to deepen the analysis of data information, and to improve the customer's website retrieval effect.

In addition, we can put in advertisements regularly, according to the results of the operation of Web data mining technology, select good delivery channels, clearly grasp the relationship between advertising delivery and transaction achievement rate, and improve the level of advertising delivery. It should be noted that the staff should realize the importance of network security, strengthen firewall design, use data mining technology, analyze abnormal access and invalid data, find out potential security risks in time, propose solutions, establish protective system, and maintain electronic transaction security [6].

\section{Conclusion}

To sum up, in the context of the rapid development of information, e-commerce has become one of the main ways of trade in today's society, which has an important role in promoting the steady growth of our national economy. According to the basic characteristics of e-commerce, if the staff want to deal with a large amount of data information effectively and improve the efficiency and quality of work, it is necessary to introduce Web data mining technology and establish a data processing system in line with the development trend of e-commerce trade. In the actual process, the staff should grasp the characteristics and basic needs of the target customer group and carry out personalized service according to the actual trade content of their own enterprises, and strengthen the construction of website functions and characteristics to improve the rate of electronic transaction achievement.

\section{References}

[1] Zhu Sha. Application Analysis of Computer Web Data Mining Technology in Electronic Commerce. Computer Knowledge and Technology, vol. 15, no. 32, pp. 287-288, 2019.

[2] National Front. Research on the Application of Data Mining Technology in Electronic Commerce. Computer Knowledge and Technology, vol. 15, no. 24, pp. 280-281, 2019.

[3] Ye Nanjun. Analysis on the Application of Data Mining Technology in Electronic Commerce. Information Records, vol. 20, no. 06, pp. 137-138, 2019.

[4] Gao Yu, Yan Juanjuan, Sun Jian. A probe into the fit of E-commerce management and Web data mining technology. Industry and Technology Forum, vol. 18, no. 11, pp. 57-58, 2019.

[5] Gao Yu, Wang Jinhong, Ma Bin. Application of data mining technology in e-commerce management. IC Applications, vol. 36, no. 04, pp. 65-66, 2019.

[6] Liu Yadong. Research on the Application of Web Data Mining Technology in Electronic Commerce. Electronic World, no. 06, pp. 154-155, 2019. 